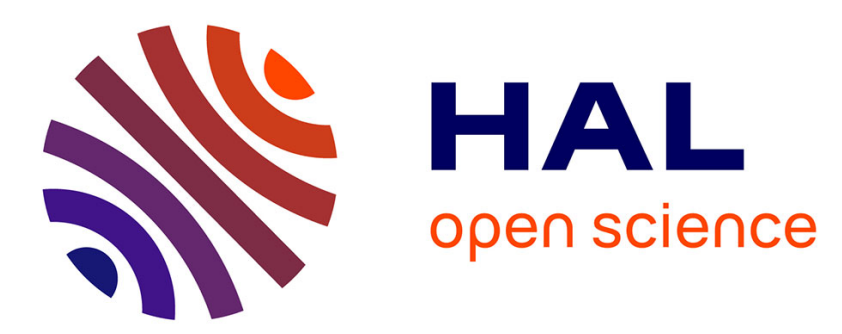

\title{
Detecting PCB Assembly defects using infrared thermal signatures
}

Nabil El Belghiti Alaoui, Patrick Tounsi, Alexandre Boyer, Arnaud Viard

\section{To cite this version:}

Nabil El Belghiti Alaoui, Patrick Tounsi, Alexandre Boyer, Arnaud Viard. Detecting PCB Assembly defects using infrared thermal signatures. 27th International Conference Mixed Design of Integrated Circuits and Systems (MIXDES2019), Jun 2019, Wroclaw, Poland. 10.23919/MIXDES.2019.8787089 . hal-02319460

\author{
HAL Id: hal-02319460 \\ https://hal.laas.fr/hal-02319460
}

Submitted on 18 Oct 2019

HAL is a multi-disciplinary open access archive for the deposit and dissemination of scientific research documents, whether they are published or not. The documents may come from teaching and research institutions in France or abroad, or from public or private research centers.
L'archive ouverte pluridisciplinaire HAL, est destinée au dépôt et à la diffusion de documents scientifiques de niveau recherche, publiés ou non, émanant des établissements d'enseignement et de recherche français ou étrangers, des laboratoires publics ou privés. 


\section{Detecting PCB Assembly defects using infrared thermal signatures}

\author{
Nabil EL BELGHITI ALAOUI ${ }^{1,2}$, \\ Patrick TOUNSI ${ }^{2}$, Alexandre BOYER ${ }^{2}$ \\ ${ }^{1}$ ACTIA Automotive \\ ${ }^{2}$ LAAS-CNRS \\ 31400 Toulouse, France \\ Nabil.elbelghiti-alaoui@actia.fr
}

\author{
Arnaud VIARD ${ }^{1}$ \\ ${ }^{1}$ ACTIA Automotive \\ Industrial Operations Department \\ 31400 Toulouse, France
}

\begin{abstract}
A Printed Circuit Board assembly (PCBA) testing approach using infrared thermal signatures is presented. The concept of thermal signature for PCBAs is introduced. Based on this concept, the testing method is able to: - detect assembly defects such as presence, polarity, value and solder (shorts and opens) and in some cases component health state - classify the components mounted on the PCB into a number of classes (e.g. - fault free(reliable), functional (less reliable), faulty ). According to the thermal signature of each component on the PCBA, PCBAs can be also classified in the same number of classes. In this article a special focus is put on capacitor defects especially capacitor value defects. Therefore, they will be the main components tested. The fault detection indicator used in this proof of concept is a statistical mean squared error measure (MSE).
\end{abstract}

Keywords- defect detection, PCBA testing, thermal signatures, mean squared error

\section{INTRODUCTION}

Traditional testing of printed circuit board assemblies (PCBAs) includes in-circuit test (ICT), visual inspection, $x$-ray radiography and functional test. These procedures are used to insure quality, detect and eliminate defects, and accelerate weak component failures [1], [2]. Thermal imaging is one of the types of visual inspection and indicates hot spots on operating PCBs. These hot spots indicate shorts and overstressed components [1]. Traditional inspection equipment (visible-light or x-ray) is also useful on production lines, but such systems provide only physical "tests." They can identify a fracture, a misplaced component, or missing solder, but problems such as a specific electrical short, a bad transistor, or a circuit that runs hot will all remain invisible [2]. Thermal imaging is very useful in the design and test process of PCBAs. Thermal signature analysis relies on the power dissipation of each component mounted on the PCBA. The energy consumption associated with the passage of electrons through the junctions in a semiconductor device or in a passive component gives rise to thermal characteristic of each component with respect to a certain test condition [1]. Thermal management in the design, operation, and installation of components is one of the most critical problems facing electronic designers and manufacturers. This thermal characteristic of electronic components is captured by an infrared camera and thus the thermal signature is achieved. Further, the thermal image which is the association of different components thermal signatures can be used in the testing process of PCBAs. The deviation from normal thermal dissipation pattern or normal contour is a sign of fault occurrence. The color of each pixel in an infrared image represents a certain temperature in the real environment [3]. Infrared thermal defect detection achieves its results using only the information provided by the temperature evolution over time of each tested component under a certain working conditions of the PCBA. In the process of testing this defect detection approach, we used the temperature evolution of capacitors mounted on a DC/DC boost converter board [4] as heat signatures. The usual way of using infrared testing is to compare an acquired IR signature with a statistical model computed from IR signatures obtained from a set of knowngood boards [5], [6]. The problem of this solution is to choose a proper threshold value and to compute and maintain the statistical model.

The main goal of this article is to introduce the approach of using thermal signatures of components mounted on a PCB and in order to test them in production process. In-line testing based on components signatures is not a new concept; for example, using near-field magnetic signatures is described in [7] and [8]. On the other way, thermal signatures are usually used to conduct reliability tests and failure analysis of PCBAs and uncommonly used in the production process due to test-time constraints. This article tries to introduce a new way to define thermal signatures so they can be used more properly to detect defects in PCBA production tests.

The organization of this paper is as follows. The concept of thermal signature of a PCB is introduced in the next section. Section III describes the achieved results and their analysis using the MSE indicator. Conclusions and perspectives are presented in section VI. 


\section{THE CONCEPT OF INFRARED THERMAL SIGNATURES}

In this section, we introduce the concept of using infrared thermal signatures of components mounted on a PCB in order to identify assembly defects related to component value.

Components that will be focused on in this article are input and output filtering capacitors of a DC/DC converter. In power applications these components are crucial to ensure a proper functioning and a good reliability of power management/power supply blocks. Moreover, they are usually hard to test in ICT especially when assembled in parallel groups of two or more different values. Testing them using their heat signature contactlessly will increase the testability of boards and optimize the quality of products.

\section{A. Principle}

Infrared thermal signature also called heat signature is the power dissipated by an electronic device or component by Joule effect in response to an electrical stimulus. This dissipated power is radiated three-dimensionally as an infrared wave whose the vertical component, in our case, is captured by a highly sensitive InSb IR camera [9] (see Fig. 1), which makes the IR signatures exploited one-dimensional. In this first proof of concept, the stimulus used to trigger these signatures is a typical loaded operation of the board under test (BUT).

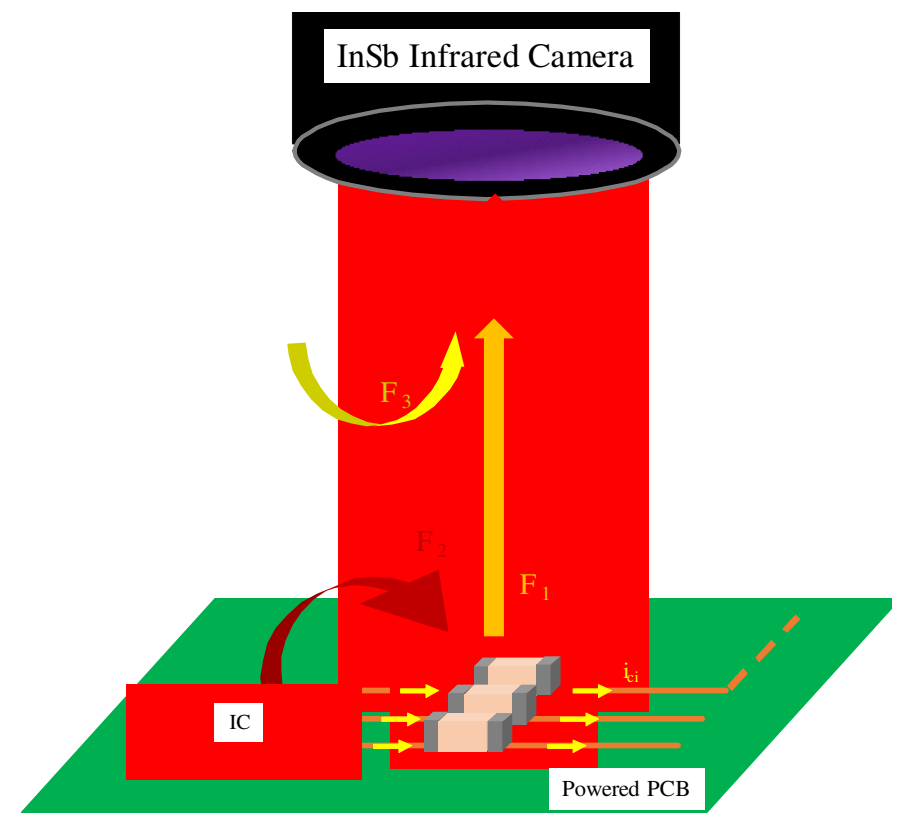

Fig. 1. One-dimensional measurement of the IR thermal signature of a group of capacitors; with $\Phi_{1}, \Phi_{2}, \Phi_{3}, \Phi_{\mathrm{T}}$ being respectively: the heat flux of components, heat flux of adjacents components, surrounding thermal noise, the total heat flux measured by the camera.

Detecting defective signatures will be achieved by comparing measured signatures to registered reference signatures. MSE indicator is a simple yet effective tool to compare signatures in this simple chosen defect cases. They will be detailed in the next section.

\section{B. Case study \& Test bench description}

The set up used to prove the concept of this testing technique is shown in Fig.2. A highly sensitive mid-wave infrared (MWIR) camera which is equipped with cooled indium antimonide detectors that can detect temperature differences of less than $25 \mathrm{mK}$. The camera produces temperature measurements with an accuracy of $\pm 1^{\circ} \mathrm{C}$ and gives a wide temperature range that is automatically adjusted to best fit the thermal scene. A close-up lens (MW50MM) [10] is attached to the camera to achieve the necessary field-of-view. The frame rate was set-up at $25 \mathrm{~Hz}$ and the integration time at $2 \mathrm{~ms}$ because of the low operating frequency of the BUT and the low heating speed of the components tested.

The technique was tested on two different DC/DC converter boards with different topologies: a DC/DC buck converter and a DC/DC boost converter. The detection results were significant and very similar on both cases, therefor, only results from the last board which is a DC/DC boost converter board (see Fig. 3) are presented. This board steps up a 3,6V input to a $9 \mathrm{~V}$ output voltage at $170 \mathrm{kHz}$ switching frequency [11].

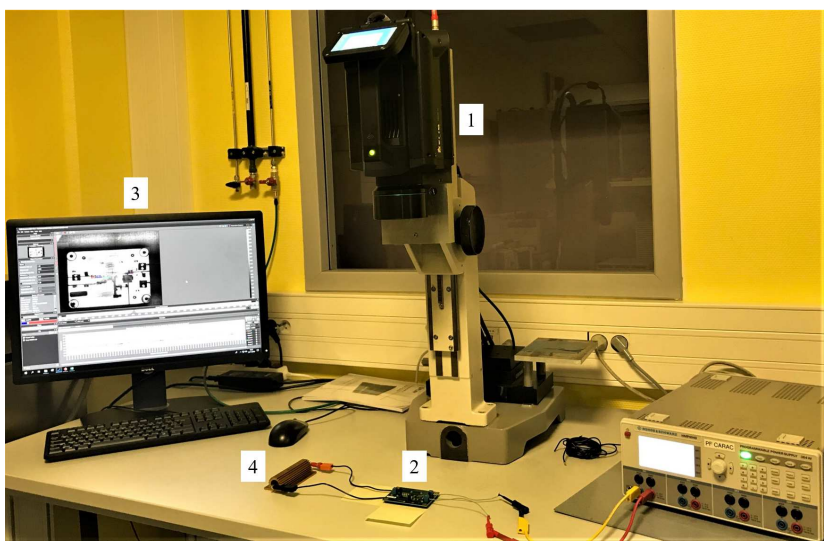

Fig. 2. Figure showing the test bench, 1: the IR camera, 2: the BUT under test, 3: computer station controlling the camera and the data

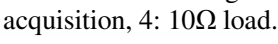

The camera measures the temperature evolution over input and output capacitors under normal operating and loading conditions, which are summarized in Table 1. These measurements, which characterize each capacitor mounted on the board, will be referred to as infrared thermal signatures (IRTS).

TABLE I. OPERATING AND LOADING CONDITIONS

\begin{tabular}{|l|l|}
\hline Input voltage / Output voltage & $3.6 \mathrm{~V} / 9 \mathrm{~V}$ \\
\hline Input current / Output Current & $2.5 \mathrm{~A} / 0.9 \mathrm{~A}$ \\
\hline Resistive load & $10 \Omega$ \\
\hline Room temperature & $23^{\circ} \mathrm{C}$ \\
\hline
\end{tabular}




\section{Test procedure:}

The test procedure used to prove the concept of the IRTS testing technique is shown in Fig. 3.

First, to prove the repeatability of measurements and to prove that the IRTS' variations are not due to solder quantity used to mount the tested capacitors (see Fig. 4), reference value capacitors $(22 \mu \mathrm{F})$ were desoldered and soldered repetitively while measuring IRTS' between each maneuver using the same lead-free solder. The MSE was calculated for four repetitions of this first procedure.

Second, reference capacitors were desoldered and replaced by capacitors with the same dielectric technology and various defect values $(4.7 \mu \mathrm{F}, 15 \mu \mathrm{F}, 33 \mu \mathrm{F})$ separately and IRTS were measured for all input/output capacitors at each defect value. Capacitors were changed independently at each measurement campaign for each defect value. Results for 3 defect values for each $\mathrm{C} 1$ and $\mathrm{C} 4$ are presented in section III.

Third, MSE was calculated for every capacitor in comparison with the reference IRTS'. Conclusions about the capacitor's value mounted on the PCB (Fault-free / Faulty) were made based on this comparison.

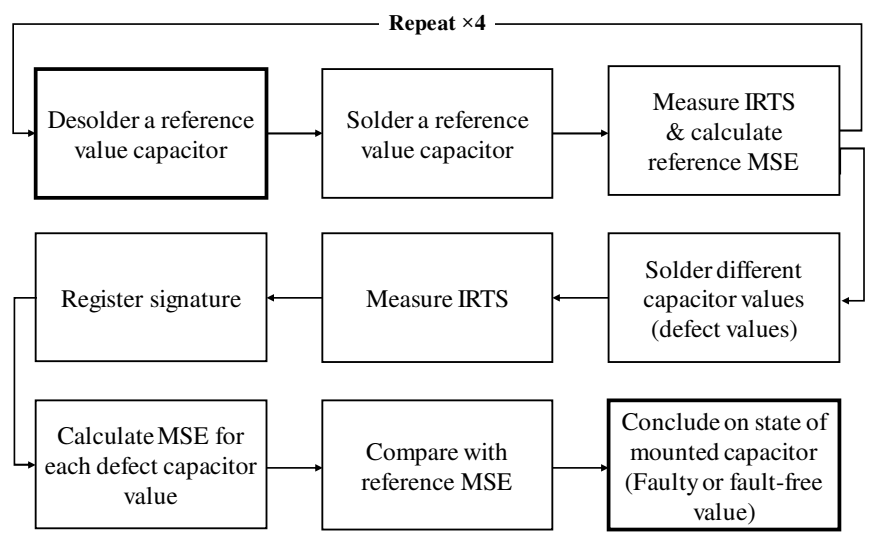

Fig. 3. Test procedure used to prove the concept of the IRTS testing technique.

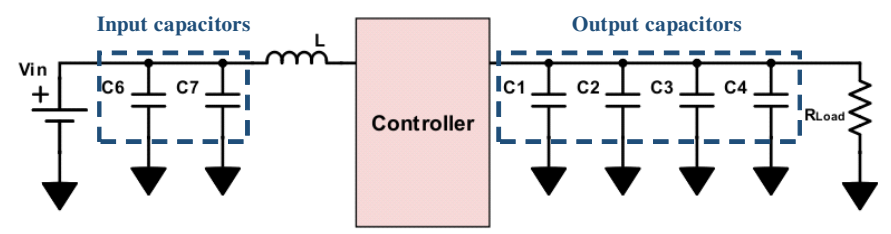

Fig. 4. Simplified diagram of the BUT: DC/DC boost converter showing the tested capacitors.

\section{RESULTS AND ANALYSIS}

The results presented in this section show that varying an input/output filtering capacitor value (C) has a direct influence on its temperature evolution (Tc) over time. The dissipated power depends on the equivalent series resistance (ESR) and the RMS current ( $i_{\text {cRMS }}$ ) flowing through the capacitor (see equation 1). The RMS current depends on capacitor's value (see equation 2). Thus, the evolution of the temperature is also dependent on the value of the capacitor (see equation 3). A variation of the dissipated power captured by the IR camera serves as an indicator of value or solder (short / open) related defects.

$$
i_{c R M S}(C)=\sqrt{\frac{\mathbf{1}}{T} \int_{0}^{T}\left|j C w \times v_{c}(t)\right|^{2} \cdot d t}
$$

Care was taken to choose ceramic capacitors that have the same dielectric technology (see Table 2) in order to limit deviations due to value tolerance and temperature performance drift.

TABLE II. CERAMIC CAPACITORS CHARACTERISTICS

\begin{tabular}{|l|l|l|l|}
\hline $\begin{array}{c}\text { C1 \& C4 } \\
\text { values }(\boldsymbol{\mu F})\end{array}$ & \multicolumn{1}{|c|}{ Technology } & \multicolumn{1}{|c|}{ Package } & Tolerance \\
\hline 4.7 & X7R & 1210 & $10 \%$ \\
\hline 15 & X7R & 1210 & $10 \%$ \\
\hline 22 (Reference) & X7R & 1210 & $10 \%$ \\
\hline 33 & X7R & 1210 & $10 \%$ \\
\hline
\end{tabular}

\section{A. Experimental results and analysis}

The software controlling the camera "ResearchIR" provides different pixel averaging cursors to measure the temperature evolution on the IR thermal image (see Fig. 5). A $3 \times 3$ pixels averaging cursor was put on each tested capacitor and the results of the first verification of the test procedure as mentioned in the first paragraph of part $\mathrm{C}$ are shown below (see Fig. 6).

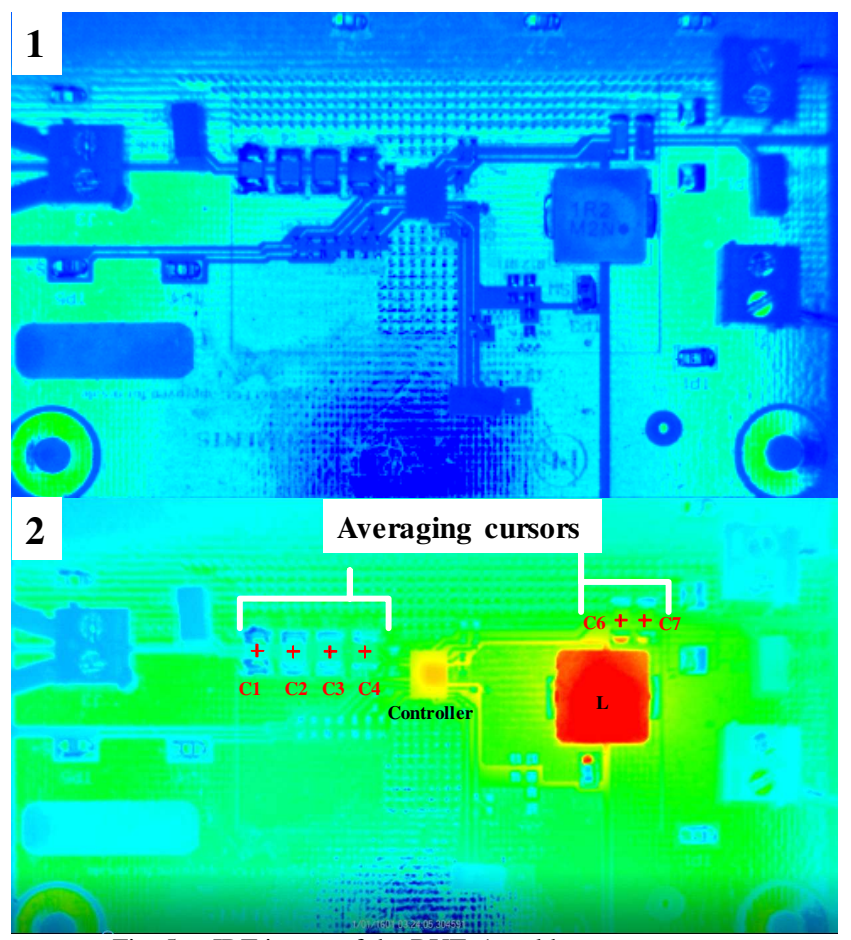

Fig. 5. IRT image of the BUT, 1: cold state, no power; 2 : operating state, powered. 


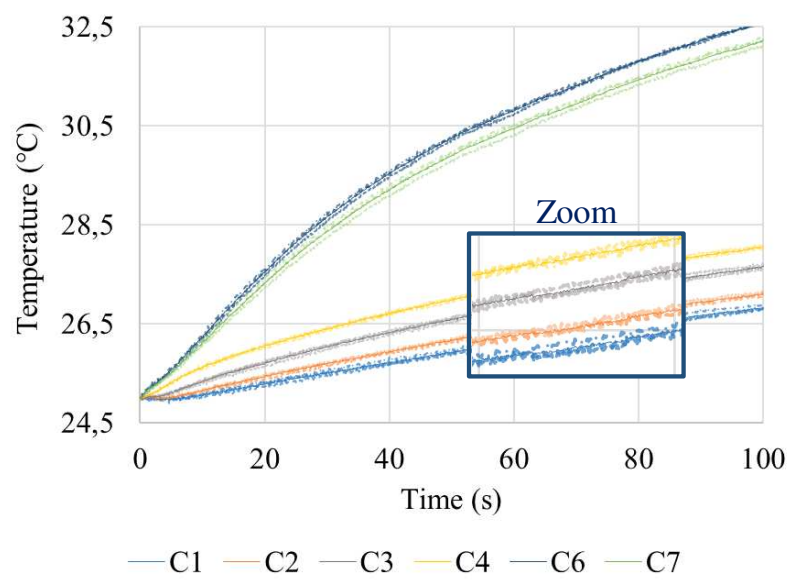

Fig. 6. Figure showing IRTS variation (doted lines) of all capacitors when desoldering and soldering $\mathrm{C} 1$ four times with the same reference value.

These variations are mainly due to the uncertainties related to the position of the soldered capacitors. Calculating the average MSE [13] of the IRTS variation over each tested capacitor gives an average MSE threshold (MSETH) of 0.05 for each tested capacitor. This value will serve as a comparison value to detect signature variations when mounting a wrong value capacitor.

\section{a) Refrence Infrared Thermal Signatures:}

The averaging of the four IRTS measurements over each capacitor is presented in Fig.7 and used as fault-free reference IRTS'. For test in production, time constraints must be considered, which can vary from a manufacturer to another. An IRTS measurement over forty seconds was judged sufficient and can be optimized in function of the type of the BUT and the tested components.

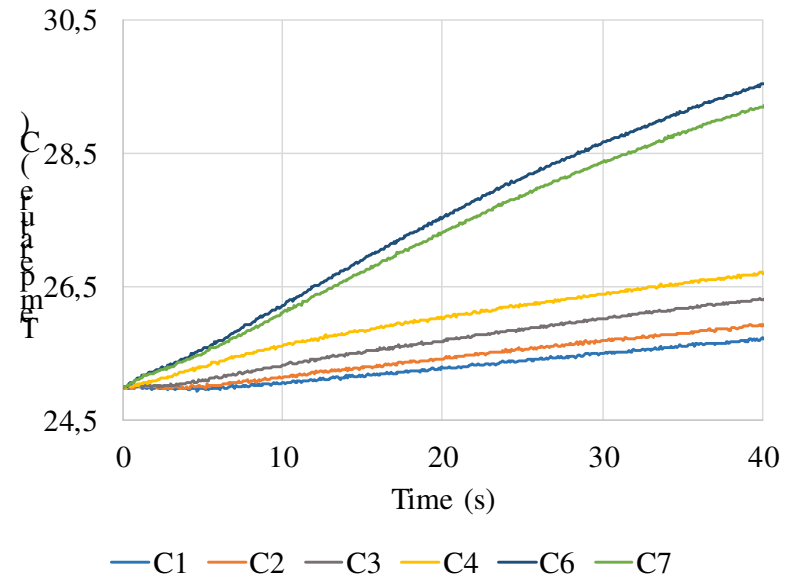

Fig. 7. Reference IRTS' of each input/output capacitor.

\section{b) Value defect in input capacitor C4:}

As discussed in the second paragraph of part $\mathrm{C}$, three faulty capacitor values were tested for $\mathrm{C} 1$ and $\mathrm{C} 4$. The results reflecting the IRTS variation over $\mathrm{C} 4$ are presented in Fig.8. Comparing between the calculated MSE for each component in this defect case is presented as a bar plot in Fig.9.

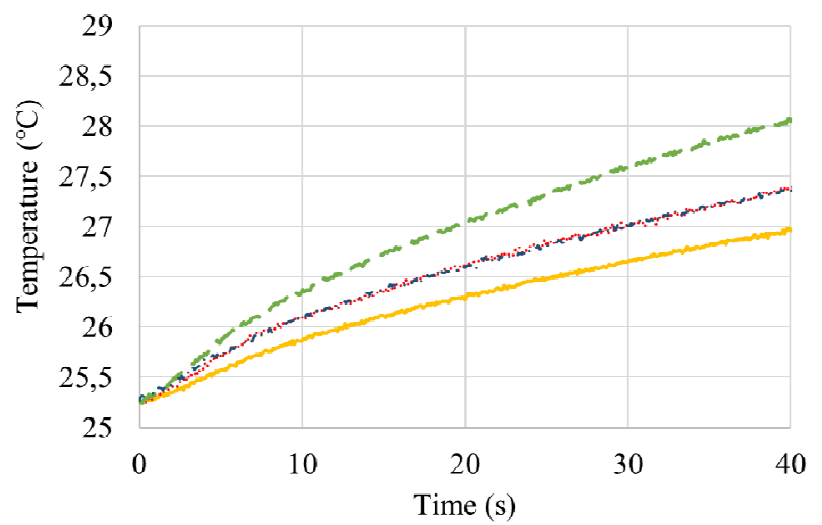

$-\mathrm{C} 4=22 \mu \mathrm{F}$ (Ref) $\cdots \cdots \cdot \mathrm{C} 4=4.7 \mu \mathrm{F}--\mathrm{C} 4=15 \mu \mathrm{F}-\cdot \mathrm{C} 4=33 \mu \mathrm{F}$

Fig. 8. IRTS measured over $\mathrm{C} 4$ for three defect values in comparison with the reference IRTS.

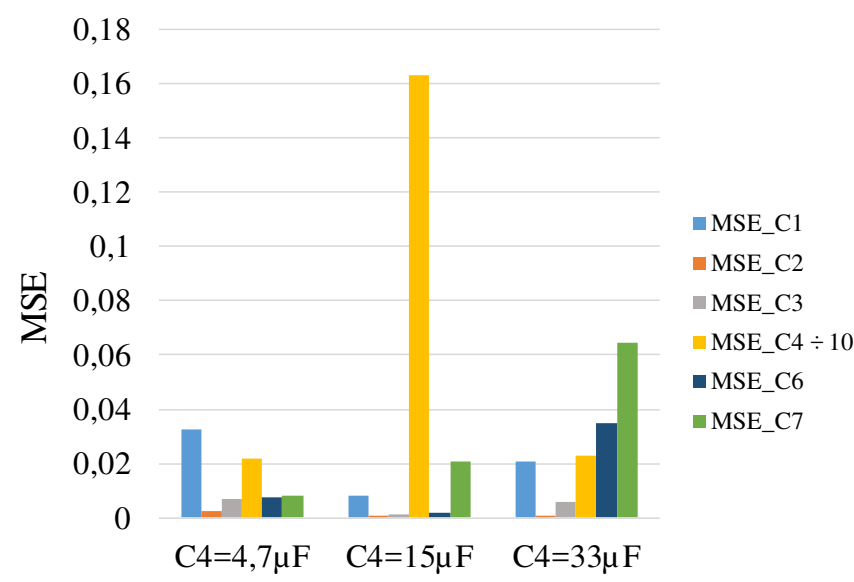

Defect value introduced

Fig. 9. MSE calculated for each input/output filtering capacitor for three defected values of capacitor $\mathrm{C} 4$

Comparing the MSE calculated for each component shows that the highest MSE value (MSE_C4) corresponds to the defected capacitor $\mathrm{C} 4$ for all the three defected values. The MSE_C4 value was divided by 10 in order to fit into the comparison scale.

c) Value defect in input capacitor Cl:

Same thing goes for the filtering capacitor C1. Fig.10 reflects the IRTS variation over $\mathrm{C} 1$ and Fig.11 shows a comparison between each calculated MSE.

Using the mean squared error in these simple defect cases reveals a significant difference. Although, a normalization of the data around the same starting room temperature $\left(25^{\circ} \mathrm{C}\right)$ was necessary to achieve results that are more precise. The deviation of MSE over unchanged capacitors is very low, while the variation over $\mathrm{C} 1$ for the faulty values is very high. The MSE value over $\mathrm{C} 1$ was divided by 10 in order to fit into the comparison plot scale. 


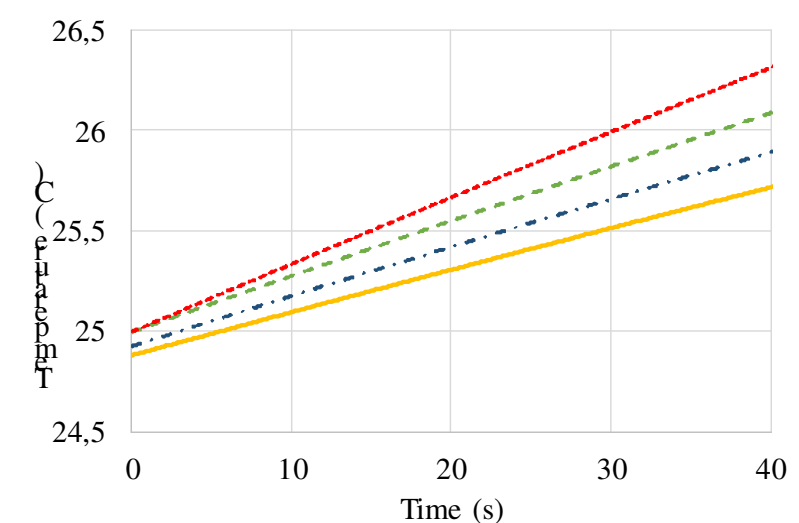

- - $\mathrm{C} 1=15 \mu \mathrm{F}-\cdot-\cdot \mathrm{C} 1=4,7 \mu \mathrm{F}-\mathrm{C} 1=22 \mu \mathrm{F}(\mathrm{Ref})-\cdot-\mathrm{C} 1=33 \mu \mathrm{F}$

Fig. 10. IRTS measured over $\mathrm{C} 1$ for three defect values in comparison with the reference IRTS.

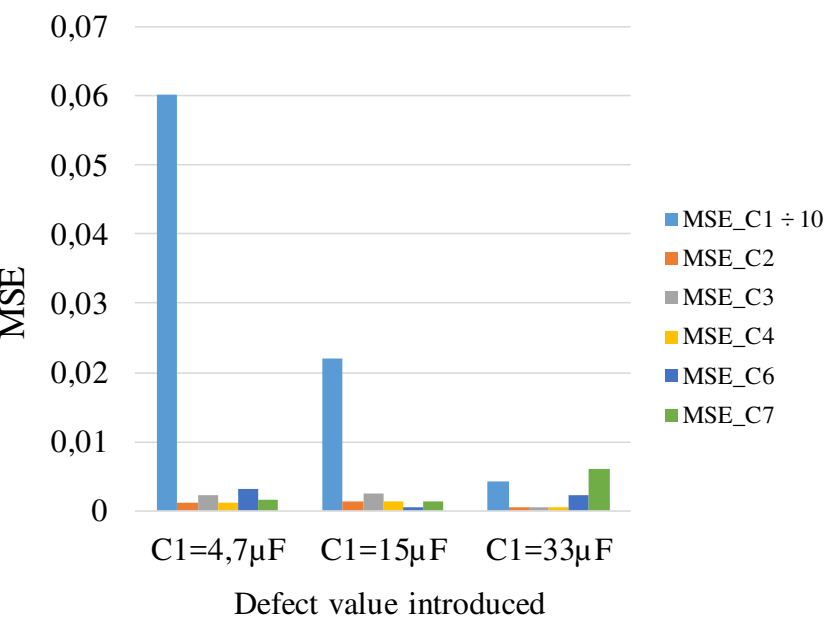

Fig. 11. MSE calculated for each input/output filtering capacitor for three defected values of capacitor $\mathrm{C} 1$

\section{CONClusions ANd PERSPECTIVES}

We presented the possibility of using infrared thermal signatures to diagnose faulty capacitors contactlessly on a limited physical access PCBA. It can also detect missing, short-circuited and overstressed components. This approach proposes to overcome the limitations of classical inspection techniques, which are limited to providing only a physical test of certain components mounted on the BUT. A simple statistical indicator was used to compare measured signatures and has given satisfactory results for simple defect cases.

This first experimental result demonstrates that infrared thermal signature approach here presented can provide a viable alternative to detect specific component level defects and decrease the number of traditional test points while still provide improved access.
Thermal testing is a very time consuming test method due to the large delays of thermal phenomena which changes from a BUT to another, which makes it the main drawback of this approach.

Further work will focus on detecting more complex assembly defects using a lower inspection time. For more complex defect combinations, multi-physical modeling is required to simulate multiple cases of defects at once. Measurements must then be processed using a fast and robust outlier detection algorithm, since there are different correlations between the currents flowing through the tested components and consequently between the IRTS'.

\section{ACKNOWLEDGMENT}

This work was supported by the National Association of Research and Technology (ANRT) and the characterization platform of LAAS-CNRS.

\section{REFERENCES}

[1] M. Moganti, F. Ercal, C. Dagli, S. Tsunekawa, "Automatic PCB Inspection Algorithms: A Survey", Computer Vision and Image Understanding, Vol. 63, No. 2, pp. 287-313, 1996.

[2] J. Sexton, "Infrared Inspection Finds Elusive Faults", Test \& Measurement World, 2001.

[3] M. Vladutiu, H. Moldovan and M. Marcu, "A New Method of Testing Using Infrared Images", CONTI 2000

[4] Texas Instruments website, Power management products: http://www.ti.com/lit/ds/symlink/tps61088.pdf 2019, (accessed January 2019)

[5] H. Moldovan, M. Marcu and M. Vladutiu, "PCB Testing Using Infrared Thermal Signatures," 2005 IEEE Instrumentationand Measurement Technology Conference Proceedings, Ottawa, Ont., 2005, pp. 19701974. doi: 10.1109/IMTC.2005.1604516

[6] J. Altet, A. Rubio, E. Schaub, S. Dilhaire, W. Claeys, "Thermal Testing: Fault Location Strategies", 18th VLSI Test Symposium, p. 189-193, Apr. 2000.

[7] N. El Belghiti Alaoui, A. Boyer, P. Tounsi, A. Viard, "Upgrading InCircuit Test of high density PCBAs using electromagnetic measurement and Principal Component Analysis", Journal of Electronic Testing, December 2018, Volume 34, Issue 6, pp 749-762

[8] N. El Belghiti Alaoui, P. Tounsi, A. Boyer and A. Viard, "New testing approach using near electromagnetic field probing intending to upgrade in-circuit testing of high density PCBAs," 2018 IEEE 27th North Atlantic Test Workshop (NATW), Essex, VT, 2018, pp. 1-8. doi: 10.1109/NATW.2018.8388867S.

[9] Flir Systems website, R\&D and science products, https://www.flir.com/globalassets/imported-assets/document/flirx6570sc-user-manual.pdf 2018, (accessed January 2019)

[10] Flir Systems website, R\&D and science products, http://www.nbn.at/fileadmin/user upload/Vertretungen/FLIR/X6900sc/ Datasheets/X6540sc_66701-0101-en-US_A4-1706-nbn.pdf 2017, (accessed January 2019)

[11] Texas Instruments website, Power management products: http://www.ti.com/lit/ug/slvuaf2/slvuaf2.pdf 2015, (accessed January 2019) 